Acta Crystallographica Section F

Structural Biology

and Crystallization

Communications

ISSN 1744-3091

Joseph A. Newman, Sanjan K. Das, Svetlana E. Sedelnikova and David W. Rice*

Krebs Institute for Biomolecular Research, Department of Molecular Biology and Biotechnology, The University of Sheffield, Sheffield S10 2TN, England

Correspondence e-mail:d.rice@sheffield.ac.uk

Received 26 May 2006

Accepted 4 September 2006
C 2006 International Union of Crystallography All rights reserved

\section{Cloning, purification and preliminary crystallographic analysis of a putative pyridoxal kinase from Bacillus subtilis}

Pyridoxal kinases (PdxK) are able to catalyse the phosphorylation of three vitamin $\mathrm{B}_{6}$ precursors, pyridoxal, pyridoxine and pyridoxamine, to their $5^{\prime}$-phosphates and play an important role in the vitamin $\mathrm{B}_{6}$ salvage pathway. Recently, the thiD gene of Bacillus subtilis was found to encode an enzyme which has the activity expected of a pyridoxal kinase despite its previous assignment as an HMPP kinase owing to higher sequence similarity. As such, this enzyme would appear to represent a new class of 'HMPP kinase-like' pyridoxal kinases. B. subtilis thiD has been cloned and the protein has been overexpressed in Escherichia coli, purified and subsequently crystallized in a binary complex with ADP and $\mathrm{Mg}^{2+}$. X-ray diffraction data have been collected from crystals to $2.8 \AA$ resolution at $100 \mathrm{~K}$. The crystals belong to a primitive tetragonal system, point group 422, and analysis of the systematic absences suggest that they belong to one of the enantiomorphic pair of space groups $P 4_{1} 2_{1} 2$ or $P 4_{3} 2_{1} 2$. Consideration of the space-group symmetry and unit-cell parameters $\left(a=b=102.9, c=252.6 \AA, \alpha=\beta=\gamma=90^{\circ}\right)$ suggest that the crystals contain between three and six molecules in the asymmetric unit. A full structure determination is under way to provide insights into aspects of the enzyme mechanism and substrate specificity.

\section{Introduction}

Pyridoxal kinase $(\mathrm{PdxK})$ is an enzyme that functions in the salvage pathway of pyridoxal 5'-phosphate (PLP). PdxK catalyses the phosphorylation of pyridoxal, pyridoxine and pyridoxamine to their corresponding 5'-phosphates, which are precursors for the active form of vitamin $\mathrm{B}_{6}$ (Fig. 1). PLP is required by both prokaryotes and eukaryotes for the synthesis, conversion and catabolism of amino acids and can be synthesized de novo by many bacteria as well as salvaged from the growth medium. In Escherichia coli, two pyridoxal kinase genes have been identified and named PdxY (Yang et al., 1998; Safo et al., 2004) and PdxK (Yang et al., 1996). PdxY is a pyridoxal kinase which like PdxK is involved in the PLP-salvage pathway, but is not able to catalyse the phosphorylation of the additional substrates pyridoxine and pyridoxamine. PdxK has also been shown to play a role in the thiamine phosphate-salvage pathway and possesses 4-amino-5-hydroxymethyl-2-methylpyrimidine (HMP) kinase activity (Begley et al., 1999; Mizote \& Nakayama, 1989).

The thiD gene has been previously classified in studies from a number of different species as encoding a 4-amino-5-hydroxymethyl2-methylpyrimidine phosphate kinase (HMPP kinase), which is an enzyme that functions in the thiamine phosphate (vitamin $\mathrm{B}_{1}$ ) salvage pathway and is essential for the survival and virulence of a number of pathogens (Hava \& Camilli, 2002; Akerley et al., 2002). HMPP kinases are able to catalyse the phosphorylation of the hydroxymethyl group on HMP and also the subsequent phosphorylation of a phosphomethyl group on HMPP, but do not have any known activity for phosphorylating pyridoxal, pyridoxine or pyridoxamine. The product of the Bacillus subtilis thiD gene comprises a $29 \mathrm{kDa}$ protein of 271 amino acids which is unable to catalyse the phosphorylation of HMPP as suggested by its genome annotation, but instead possesses the enzyme activity of a pyridoxal kinase (Park et al., 2004). This confusion arose as a result of its higher sequence identities to HMPP kinases than to pyridoxal kinases (35 and $25 \%$, respectively, for the 
<smiles>Cc1ncc(CO)c(C=O)c1O</smiles>

Pyridoxal<smiles>Cc1ncc(CO)c(CO)c1O</smiles>

Pyridoxine<smiles>Cc1ncc(CO)c(CN)c1O</smiles>

Pyridoxamine

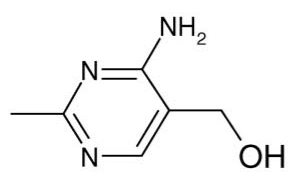

HMP

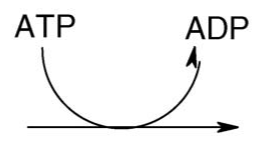

PdxK

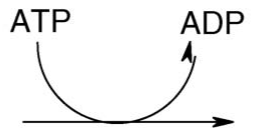

PdxK

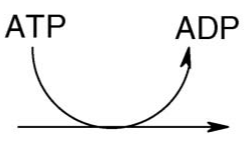

PdxK

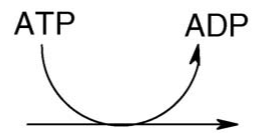

PdxK<smiles>Cc1ncc(COP(=O)([O-])[O-])c(C=O)c1O</smiles>

Pyridoxal 5'-phosphate<smiles>Cc1ncc(COP(=O)([O-])[O-])c(C(O)O)c1O</smiles>

Pyridoxine 5'-phosphate<smiles>Cc1ncc(COP(=O)([O-])[O-])c(CN)c1O</smiles>

Pyridoxamine 5'-phosphate<smiles>Cc1ncc(COP(=O)([O-])[O-])c(N)n1</smiles>

HMP-P

Figure 1

The four kinase reactions catalysed by PdxK.

E. coli enzymes). The $B$. subtilis thiD gene product will therefore be referred to as PdxK for the remainder of this paper.

Analysis of the amino-acid sequence of PdxK has suggested that it is a member of the ribokinase superfamily and this has been confirmed by the determination of the structure of PdxKs from sheep brain (Li et al., 2002, 2004), human (PDB code 2ajp) and E. coli (Safo et al., 2006) and the PdxY gene product in E. coli (Safo et al., 2004). However, comparing the sequences of these enzymes to that of B. subtilis PdxK, the well aligned regions flanking the substratebinding site reveal that few of the key residues involved in substrate recognition or catalysis are conserved (Fig. 2). Specifically, three residues involved in forming interactions with the substrate (Ser12, Thr47 and Tyr84 in the sheep brain enzyme) are completely conserved in all PdxKs studied to date but are not present in B. subtilis PdxK (Gly11, Pro46, Met82). Furthermore, the catalytic machinery of these enzymes is also different, with the sheep, human and E. coli enzymes having a catalytic Asp, whereas the B. subtilis enzyme has a Cys at this position. Interestingly, at each of these positions the sequence of $B$. subtilis $\mathrm{PdxK}$ is very similar to that found in the family of HMPP kinases (for example, E. coli ThiD). This suggests that $B$. subtilis PdxK may be a representative member of a new class of 'HMPP kinase-like' pyridoxal kinases for which no structural data currently exists. The closer sequence similarities found between $B$. subtilis PdxK and other HMPP kinases may indicate that pyridoxal kinase activity has evolved independently on multiple occasions during evolution.

To date, there is no structural data on the mode of nucleotide binding to any HMPP kinase and analysis of the apoenzyme structures [from Salmonella typhimurium (Cheng et al., 2002) and Thermus thermophilus (PDB code 1ub0)] has revealed that two loops which lie close to the nucleotide-binding site are disordered. The structure of a nucleotide complex may shed light on the role of these loops, which are thought to become ordered upon nucleotide binding and play a role in nucleotide recognition.

Figure 2

Multiple sequence alignment showing the sequence conservation in four different regions for PdxK from sheep, E. coli and B. subtilis and E. coli ThiD. Identical residues across all sequences are shown in reverse type on a dark background. Strongly conserved residues are shown in bold. Residues that have been identified from previous structural studies on sheep and E. coli PdxK to form interactions with the substrate are highlighted by grey boxes and can be seen to be different in $B$. subtilis PdxK, where they are more similar to E. coli ThiD. The sequences were aligned using ClustalW (Thompson et al., 1994) and the figure was prepared using ESPript (Gouet et al., 1999). 
As a contribution towards understanding the structure-function relationship of the enzyme and the molecular basis of substrate specificity, we have initiated the structure determination of $B$. subtilis $\mathrm{PdxK}$. In this paper, we describe the cloning, overexpression, purification, crystallization and preliminary X-ray analysis of this enzyme in the presence of ADP and $\mathrm{Mg}^{2+}$.

\section{Cloning, overexpression and purification of $B$. subtilis PdxK}

The B. subtilis thiD gene was PCR-amplified directly from the genomic DNA of $B$. subtilis strain 168 with the primers TCGGCGGCATATGTCTATGCATAAAGCACT (forward) and ACACAGAlTCTTATGATTGTTGATTCAGGCG (reverse). The PCR product $(813 \mathrm{bp})$ was purified (Quiagen) and a parallel restriction digest ( $310 \mathrm{~K}$ overnight) of the PCR product and plasmid vector pTB361 was performed to produce linear fragments with sticky ends suitable for ligation. The restriction products were ligated together using a gene:plasmid DNA ratio of $2: 1$ at $287 \mathrm{~K}$ and subsequently transformed into E. coli DH5 $\alpha$ for verification by PCR screening and restriction-enzyme digestion. For overexpression, the plasmid was transformed into E. coli strain BL21 (DE3). A $250 \mathrm{ml}$ flask containing $50 \mathrm{ml} \mathrm{LB}$ medium with $50 \mu \mathrm{g} \mathrm{ml}^{-1}$ tetracycline was inoculated with a single colony of the transformed strain and grown overnight at $310 \mathrm{~K}$

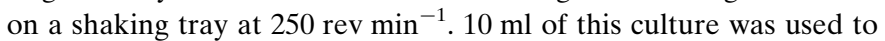
inoculate five 21 flasks each containing $450 \mathrm{ml}$ of LB medium supplemented with tetracycline as above. Cultures were grown until the absorbance at $600 \mathrm{~nm}$ reached 0.6 , at which point overexpression was induced by the addition of $0.1 \mathrm{~m} M$ IPTG. Cultures were harvested after a further $5 \mathrm{~h}$ by centrifugation at $5000 \mathrm{~g}$ for $20 \mathrm{~min}$ at $277 \mathrm{~K}$ and the pellets were frozen immediately. Analysis of the soluble fraction by SDS-PAGE showed a large overexpression band corresponding to the expected molecular weight of the enzyme ( $\sim 30 \mathrm{kDa})$.

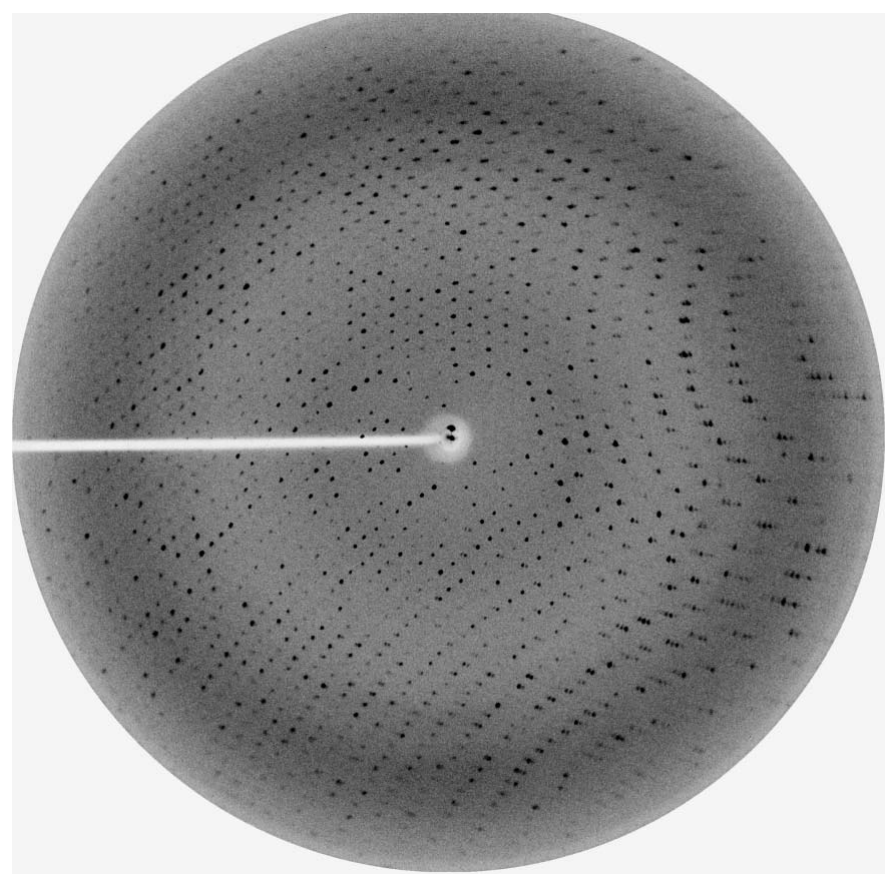

Figure 3

$0.5^{\circ}$ oscillation diffraction image of crystals of the PdxK-ADP- $\mathrm{Mg}^{2+}$ complex. The edge of the plate is set at $3.0 \AA$ resolution.
Cells containing overexpressed $\mathrm{PdxK}$ were thawed on ice, suspended in $50 \mathrm{mM}$ Tris- $\mathrm{HCl} \mathrm{pH} 8.0$ and disrupted by ultrasonication $(3 \times 20 \mathrm{~s}$ pulses $)$. Cell debris was removed by centrifugation at $20000 \mathrm{~g}$ for $20 \mathrm{~min}$. The supernatant fraction was applied onto a column packed with DEAE-Sepharose Fast Flow (Amersham Biosciences) and proteins were eluted with a linear gradient of $\mathrm{NaCl}$ from 0 to $1 M$ in $50 \mathrm{~m} M$ Tris- $\mathrm{HCl} \mathrm{pH}$ 8.0. Fractions containing PdxK were combined and 4.0 $\mathrm{M} \mathrm{NH}_{4} \mathrm{SO}_{4}$ was added to give a final concentration of $1.5 \mathrm{M}$. Precipitated proteins were removed by ultracentrifugation at $20000 \mathrm{~g}$ for $5 \mathrm{~min}$. The supernatant fraction was then loaded onto a column packed with Phenyl ToyoPearl 650S (Tosoh) and eluted with a linear gradient of $\mathrm{NH}_{4} \mathrm{SO}_{4}$ from 1.5 to $0 M$ in $50 \mathrm{~m} M$ Tris- $\mathrm{HCl}$ pH 8.0 and $200 \mathrm{~m} M \mathrm{NaCl}$. Fractions containing PdxK were pooled and concentrated using a VivaSpin $10000 \mathrm{kDa}$ molecular-weight cutoff concentrator to a final volume of $0.5 \mathrm{ml}$ and a protein concentration of $13 \mathrm{mg} \mathrm{ml}^{-1}$. The sample was then loaded onto a Hi-Load Superdex 200 column (Amersham Biosciences) equilibrated with $200 \mathrm{mM} \mathrm{NaCl}$ in $50 \mathrm{mM}$ Tris- $\mathrm{HCl} \mathrm{pH} 8.0$ and eluted with the same buffer. The elution volume was compared to a standard curve and PdxK ran with an approximate molecular weight of $40 \mathrm{kDa}$. Peak fractions containing PdxK were collected and concentrated to $10-15 \mathrm{mg} \mathrm{ml}^{-1}$ as above, exchanging to buffer containing $10 \mathrm{~m} M$ Tris- $\mathrm{HCl} \mathrm{pH} 8.0$ and $50 \mathrm{mM} \mathrm{NaCl}$. The purity of the final preparation was estimated to be over $90 \%$ by SDS-PAGE, with a yield of approximately $20 \mathrm{mg}$ per gram of cell paste.

\section{Crystallization and preliminary X-ray analysis}

An initial crystallization screen was attempted using the hangingdrop vapour-diffusion method at $290 \mathrm{~K}$ and crystallization kits from Hampton Research in the presence and absence of the nucleotides ADP, ATP, AMP-PNP and ATP $\gamma \mathrm{S}$ with and without $\mathrm{Mg}^{2+}$. Initial rodlike crystals of the free enzyme with approximate dimensions $5 \times 5 \times$ $50 \mu \mathrm{m}$ were observed to have grown in $30 \%$ PEG 4000, $0.2 \mathrm{M}$ sodium acetate trihydrate, $0.1 M$ Tris- $\mathrm{HCl} \mathrm{pH}$ 8.0. Crystals of the PdxKADP- $\mathrm{Mg}^{2+}$ complex were grown using $28 \%$ PEG 4000, $0.17 \mathrm{M}$ sodium acetate trihydrate, $0.1 \mathrm{M}$ Tris- $\mathrm{HCl} \mathrm{pH} 8.5$ as the precipitant with the addition of $10 \mathrm{mM}$ ADP, $10 \mathrm{mM} \mathrm{MgCl}$. Crystals from the latter condition were bipyramidal with approximate dimensions $60 \times$ $25 \times 25 \mu \mathrm{m}$.

Single crystals of both the free enzyme and the PdxK-ADP- $\mathrm{Mg}^{2+}$ complex were loop-mounted and placed into a cryosolution containing 27\% PEG 4000, $0.17 \mathrm{M}$ sodium acetate trihydrate, $0.08 \mathrm{M}$ Tris- $\mathrm{HCl} \mathrm{pH} 8.0,23 \%$ glycerol for approximately $2 \mathrm{~min}$. Diffraction images were collected at $100 \mathrm{~K}$ with $0.5^{\circ}$ rotations using a Rigaku MM007 rotating-anode generator with a MAR Research image-plate detector. Preliminary analysis of the X-ray diffraction data using MOSFLM (Leslie, 1992) indicated that the free-enzyme crystals belong to a primitive trigonal system, point group 312 (either $P 3_{2} 12$ or $P 3_{1} 12$ ), with unit-cell parameters $a=b=50.4, c=177.9 \AA, \alpha=\beta=90$, $\gamma=120^{\circ}$. However, the highly anisotropic nature of the diffraction and the poor resolution limit $(3.5 \AA)$ made these crystals unsuitable for detailed structural analysis.

Crystals of the PdxK-ADP- $\mathrm{Mg}^{2+}$ complex diffracted to $2.8 \AA$ (Fig. 3). Processing of the X-ray diffraction data using MOSFLM and $S C A L A$ (Evans, 1997) from the CCP4 suite of programs (Collaborative Computational Project, Number 4, 1994) and analysis of the merging statistics indicated that the crystals belong the a primitive tetragonal space group, point group 422. Further analysis of the pattern of systematic absences suggest that the crystals belong to one of the enantiomorphic pair of space groups $P 4_{1} 2_{1} 2$ or $P 4_{3} 2_{1} 2$, with 
Table 1

Data-processing statistics for $B$. subtilis $\mathrm{PdxK}-\mathrm{ADP}-\mathrm{Mg}^{2+}$ complex.

Values in parentheses are for data in the highest resolution shell.

\begin{tabular}{ll}
\hline Resolution & $20-2.8(2.95-2.8)$ \\
Independent reflections & $33604(4844)$ \\
Completeness & $99.4(99.9)$ \\
Multiplicity & $3.7(3.8)$ \\
$I / \sigma(I)$ & $9.3(2.4)$ \\
$R_{\text {merge }}^{\dagger}$ & $0.131(0.475)$ \\
\hline
\end{tabular}

$\dagger R_{\text {merge }}=\sum|I-\langle I\rangle| / \sum I$, where $I$ is the integrated intensity of a given reflection.

unit-cell parameters $a=b=102.9, c=252.6 \AA$, $\alpha=\beta=\gamma=90^{\circ}$ (datacollection statistics are shown in Table 1). Consideration of the unitcell volume and space-group symmetry suggests that the crystal contains between three and six monomers in the asymmetric unit, with a corresponding $V_{\mathrm{M}}$ range of 1.8-3.8 $\AA^{3} \mathrm{Da}^{-1}$ (Matthews, 1977). A full structure determination is under way in order to provide insights into the catalytic activity, substrate specificity and evolution of this enzyme.

This work was supported by the BBSRC. The Krebs Institute is a designated BBSRC Biomolecular Sciences Centre and a member of the North of England Structural Biology Centre.

\section{References}

Akerley, B. J., Rubin, E. J., Novick, V. L., Amaya, K., Judson, N. \& Mekalanos, J. J. (2002). Proc. Natl Acad. Sci. USA, 99, 966-971.
Begley, T. P., Downs, D. M., Ealick, S. E., McLafferty, F., Van Loon, D., Taylor, S., Chiu, H., Kinsland, C., Reddick, J., Xi, J. \& Campobasso, N. (1999). Arch. Microbiol. 171, 293-300.

Cheng, G., Bennett, E. M., Begley, T. P. \& Ealick, S. E. (2002). Structure, 10, 225-235.

Collaborative Computational Project, Number 4 (1994). Acta Cryst. D50, 760-763.

Evans, P. R. (1997). Jnt CCP4/ESF-EACBM Newsl. Protein Crystallogr. 33, $22-24$.

Gouet, P., Courcelle, E., Stuart, D. I. \& Metoz, F. (1999). Bioinformatics, 15, 305-308.

Hava, D. L. \& Camilli, A. (2002). Mol. Microbiol. 45, 1389-1405.

Leslie, A. G. W. (1992). Jnt CCP4/ESF-EAMCB Newsl. Protein Crystallogr. 26.

Li, M. H., Kwok, F., Chang, W. R., Lau, C. K., Zhang, J. P., Lo, S. C., Jiang, T. \& Liang, D. C. (2002). J. Biol. Chem. 277, 46385-46390.

Li, M. H., Kwok, F., Chang, W. R., Liu, S. Q., Lo, S. C. L., Zhang, J. P., Jiang, T. \& Liang, D. C. (2004). J. Biol. Chem. 279, 17459-17465.

Matthews, B. W. (1977). The Proteins, 3rd ed., edited by H. Neurath \& R. L. Hill,Vol. 3, pp. 468-477. New York: Academic Press.

Mizote, T. \& Nakayama, H. (1989). Biochim. Biophys. Acta, 991, 109113.

Park, J. H., Burns, K., Kinsland, C. \& Begley, T. P. (2004). J. Bacteriol. 186, $1571-1573$.

Safo, M. K., Musayev, F. N., di Salvo, M. L., Hunt, S., Claude, J. B. \& Schirch, V. (2006). J. Bacteriol. 188, 4542-4552.

Safo, M. K., Musayev, F. N., Hunt, S., di Salvo, M. L., Scarsdale, N. \& Schirch, V. (2004). J. Bacteriol. 186, 8074-8082.

Thompson, J. D., Higgins, D. G. \& Gibson, T. J. (1994). Nucleic Acids Res. 22, 4673-4680.

Yang, Y., Tsui, H. T., Man, T. K. \& Winkler, M. E. (1998). J. Bacteriol. 180, $1814-1821$.

Yang, Y., Zhao, G. \& Winkler, M. E. (1996). FEMS Microbiol. Lett. 141, 8995 . 